M. Klimczuk-Kochańska, A. Klimczuk, Trust in Food, [in:] P.B. Thompson, D.M. Kaplan (eds.), Encyclopedia of Food and Agricultural Ethics, Second Edition, Springer, Dordrecht 2019, pp. 23802386, https://doi.org/10.1007/978-94-007-6167-4_630-1.

\title{
Trust in Food
}

Andrzej Klimczuk

Collegium of Socio-Economics, Warsaw School of Economics, Warsaw, Poland

Magdalena Klimczuk-Kochańska

Faculty of Management, University of Warsaw, Warsaw, Poland

Keywords: Consumer confidence; Food risk; Food safety; Food scares

\section{Introduction}

Trust is important in the food sector. This is primarily because households entrust some of the tasks related to food preparation to food processors. The public is concerned about pesticides, food additives, preservatives, and processed foods that may harbor unwanted chemicals or additives. After numerous food scandals, consumers expect food processing industries and retailers to take responsibility for food safety. Meanwhile, the food industry focuses on profit growth and costs reduction to achieve higher production efficiency and competitiveness. It means that they introduce innovations, such as new production methods, processing techniques, and additives. Consumers have to delegate the responsibility for ensuring food safety to food producers, retailers, and regulatory authorities who ensure that the foods are safe, healthy, and pose no risks. For consumers, trusting these actors can reduce feelings of uncertainty. It is helpful for companies to be responsible for their activities through transparency and traceability. In turn, the food industry tries to gain consumers' trust by providing objective information, such as ranked brands or labels on food packages.

\section{The Concept of Trust in Food}

There are various definitions of trust (Shapiro 1987). The most recurring elements in trust definitions are (1) trust as a set of beliefs or expectations, (2) trust as a willingness to act on those beliefs and (3) trust as a dependency. Trust is related to the task of minimizing risk, for example, for consumers when they choose and use products and services. Anthony Giddens (1990) pointed at the balance between trust and acceptable risk. For understanding trust in food, we can see the link with risk assessment, as well. It results from uncertainty regarding the freshness of the food, its origin, or quality. If the above features are not met, there is a danger of, for example, food poisoning. Nevertheless, people take the risk of eating food that they have not 
M. Klimczuk-Kochańska, A. Klimczuk, Trust in Food, [in:] P.B. Thompson, D.M. Kaplan (eds.), Encyclopedia of Food and Agricultural Ethics, Second Edition, Springer, Dordrecht 2019, pp. 23802386, https://doi.org/10.1007/978-94-007-6167-4_630-1.

prepared themselves because we all have the need for daily food (Bildtgard 2008). Trust in food is seen as the main component of health creation, well-being, happiness, and pleasure.

There are three theoretical bases for trust in food: emotional, habitual, and reflexive trust. Emotional trust (basic trust) means that people trust somebody because their emotional bond demands it, and not because friends and family find them as trustworthy. We tend to rely on people whom we know to be competent, rather than the ones we know too little about to judge. They are expected to behave responsibly, honestly, and justly (Sztompka 1999). Habitual trust is based on the assumption that events occurring in the world will continue pretty much as they have before. Trust in food was created and maintained primarily through the habits generated by public ways of thinking. Until this assumption is betrayed, the trust will be habitual and automatic. The consumer does not necessarily reflect on the reasonableness of placing trust in some food brand that they choose or in the chef at a restaurant. Instead, they trust them because nothing has happened so far. Finally, trust in food is reflexive when it is consciously chosen. Giddens (1990) proposed the idea of reflexive thinking that implies that trust has acquired a conditional character and is associated with active skepticism. It can happen when, for example, there is a food scandal that caused the consumer to start considering cessation of consumption of a given type of food.

\section{Dimensions of Consumer Trust in Food}

The determinants of consumer trust include: (1) demographic determinants: age, gender, education, material status, and family life phase; (2) economic factors: income, price, products, place of sale, and advertising; (3) socio-cultural: family, opinion leaders, and reference groups; and (4) psychological factors: motives of action, needs, beliefs, and attitudes.

The above consumer characteristics in combination with dimensions of trust may contribute to the enhancement of general consumer trust in food. As a core dimension of consumer trust, the following constructs can be mentioned: (1) care and (2) openness, which make up the socalled social trust, and (3) competence - being close to the concept of confidence (Poortinga and Pidgeon 2003).

Care is associated with a consumer attitude that is related to the care of themselves. It can mean care of food value about the location of food production; used food ingredients; production environment of food; manufacture date and expiration date of food; food testing information; the transportation process of food; and the storage environment of food. 
M. Klimczuk-Kochańska, A. Klimczuk, Trust in Food, [in:] P.B. Thompson, D.M. Kaplan (eds.), Encyclopedia of Food and Agricultural Ethics, Second Edition, Springer, Dordrecht 2019, pp. 23802386, https://doi.org/10.1007/978-94-007-6167-4_630-1.

Openness indicates the need to find novel solutions, express original ideas, and employ imagination when performing tasks.

Competence is the ability, knowledge, and expertise needed by consumers to efficiently and rationally function in the marketplace. Consumers usually have a general knowledge of correct nutrition, but they scarcely use their knowledge in food decision-making and purchasing. Consequently, consumer knowledge of nutrition information and its use in food choices seems to be primarily influenced by individual features and personal conditions such as age, interest in healthy habits, and social status.

\section{Role of Industrial and Regulatory Actors in Food Supply Chain}

In food consumption, consumers trust various actors with responsibility for food production. This confidence can be regarded as a "taken-for-granted" attitude towards, for example, food buying (Grunert 2002). Confidence is based on familiarity (Siegrist et al. 2003). It is typically lost when a consumer's expectations are disappointed (Kjsmes and Dulsrud 1998). Trust involves the risk of disappointment and uncertainty and may evolve into confidence, which requires specific knowledge and faith.

As food production is increasingly taken over by the food industry, the trust might be placed in (1) regulatory authorities; (2) commercial organizations such as food producers, manufacturers, processors, retailers, and supermarkets; (3) local authorities and local chains of supply; (4) consumer movements; (5) food experts and gastronomic manuals; and (6) brands.

\section{Need to Build Trust in Food: The Causes of Consumer Distrust in Food}

The need to build trust in food may result from various situations that are encountered in the food market. Food fraud events, the introduction of new production technologies, or new food additives are particularly important.

\section{Food Fraud}

Food scares concern about the safety and quality of food. Food fraud is a dishonest act or omission relating to the production or supply of food that aims to increase personal gain, which causes damage or loss to another party. In recent years, there were a series of food scandals. One of the leading causes is the globalization of the food system that makes it harder for government agencies to live up to consumer demands for safe foods or to alleviate public concerns about food risks. Food industry fraud significantly reduced consumer confidence in 
M. Klimczuk-Kochańska, A. Klimczuk, Trust in Food, [in:] P.B. Thompson, D.M. Kaplan (eds.), Encyclopedia of Food and Agricultural Ethics, Second Edition, Springer, Dordrecht 2019, pp. 23802386, https://doi.org/10.1007/978-94-007-6167-4_630-1.

the food supply chain. The scandals have also significantly contributed to the deterioration of the overall image of the agri-food sector.

For example, in Europe, in the 1980s, there were concerns regarding the use of growthpromoting hormones in beef production, dioxins found in soft drinks, listeria outbreaks in France in 1999 and 2000, and foot and mouth disease starting in the United Kingdom. The most infamous of these was the Bovine Spongiform Encephalitis (BSE or mad cow disease) outbreak that started in the United Kingdom in 1986 and spread to other parts of Europe. In 2012, the "salt scandal" in Poland involved companies that sold chemical salt as a food salt. Another event is the 2012 counterfeit dried egg scandal: the common baking ingredient turned out to be dried fish with calcium and curcuma and only traces of egg.

\section{New Technological Systems}

Trust is crucial if consumers are to recognize and accept the benefits of new food technologies and feel assured that food regulation is protecting their best interests. However, new technological developments in the food supply may damage trust, especially when the safety of new products is questioned, as in the case where trials of genetically modified (GMO) peas were halted after an adverse immune response was detected in test animals. "Gene technology" has been portrayed as confronting the consumer with "alien" foods. In Europe, many consumers believe that technology that interferes with the laws of nature is something hazardous. Genetic engineering requires specialized knowledge, which makes it difficult for consumers to understand what it is all about, how safe GMO products are, and how they will affect human health, leading to negative perceptions toward GMO foods. Bildtgard (2008) argues that the government can have a mediating role. However, we can see the states' authority as the universal arbitrator is being challenged by some sides. In modern societies, nongovernmental organizations increasingly articulate consumer concerns about food. Those organizations, such as certification schemes, do not necessarily perceive the state as the legitimate actor for political authority.

\section{Food Additives}

The concerns regarding food production and safety may reflect consumers' lack of knowledge about the production and technology of food. Some studies have found that many consumers keep incorrect beliefs regarding food additives (e.g., the harms of artificial coloring), leading to concerns that may not be scientifically confirmed. However, scientific facts - especially when conveyed poorly or by vested interests - do not always pacify consumer worries, and often the, 
M. Klimczuk-Kochańska, A. Klimczuk, Trust in Food, [in:] P.B. Thompson, D.M. Kaplan (eds.), Encyclopedia of Food and Agricultural Ethics, Second Edition, Springer, Dordrecht 2019, pp. 23802386, https://doi.org/10.1007/978-94-007-6167-4_630-1.

legitimacy of the messenger is as necessary as that of the message. In recent years, the increasingly intensive use of food additives by enterprises has been noticed. The essential criterion for the selection of additives in the food industry should be the result of determining whether: (1) there is a technological need to use them; (2) the proposed substances and their additive content do not pose a threat to consumer health; and (3) the use of an additive to foods does not mislead the consumer as to the health quality of the food.

\section{Risk Management Tools and Building Trust in Food}

People also tend to trust institutions and information sources which are perceived to be open (Poortinga and Pidgeon 2003). Openness is related to integrity and will translate into transparency, traceability of food producers, and the use of proper labeling.

\section{Transparency}

Transparency is the extent to which an institution assesses, controls, and conveys information about risk honestly and truthfully. Providing information regarding food production to consumers is the most crucial factor in building up trust. It must be noted that trust can be destroyed when the information provided is perceived to be exaggerated, biased, or not factual. Consumers are dependent on farmers and food processors; they have difficulty assessing the ability and the desire of farmers and processors to combat food hazards, due to their lack of direct contact with them. However, consumers never have full access to knowledge of food production because information asymmetry exists between buyers and sellers. This asymmetry is considered to be the consumers' perceived risk (Bauer 1967). There are expectations that the producers should take the initiative to provide more information to increase the transparency of their activities, that is, to provide consumer guarantees for food safety, freshness, and nutrition.

Transparency is reached when everyone can always see and understand the status of an operation. Transparency may concern various issues such as transparency of supply, value, cost, the openness of the net chain, history, operation, strategy transparency, price and cost transparency, and market and product transparency. It should be noted that the level of consumer and customer expectations for transparency is not static. There are changes along with better access to various sources of information as well the different claims on benefits are getting more fully accepted and higher appreciated by the public. Also, due to the length of the supply chain in food production, it is not enough to maintain a prominent level of transparency by a single producer, but especially crucial in the agri-food sector is the transparency of all 
M. Klimczuk-Kochańska, A. Klimczuk, Trust in Food, [in:] P.B. Thompson, D.M. Kaplan (eds.), Encyclopedia of Food and Agricultural Ethics, Second Edition, Springer, Dordrecht 2019, pp. 23802386, https://doi.org/10.1007/978-94-007-6167-4_630-1.

entities in the supply chain. This can be demonstrated by application of food quality and safety standards and supply chain governance mechanisms, for example, organizational arrangements between supply chain actors for information flow and exchange.

\section{Traceability}

Traceability may be defined as the ability to identify (at all stages of production and processing) foodstuffs or feeding stuff, animal-derived agents, or other substances intended for food production. In other words, this is the ability to locate an animal, commodity, food product, or ingredient and follow its history in the supply chain forward (from source to consumer) or backward (from consumer to source). Traceability has been identified as a preventative strategy in food quality and safety management, particularly when hazards or food scares occur, in which case a suitable traceability system will facilitate timely product recall and determination of liability. Traceability should prohibit missing information in the food chain and keep the product from losing its identity. It also benefits companies, for example, in the event of a crisis to identify the source of danger in the shortest time.

In general, traceability helps to build trust, peace of mind, and confidence in the food system. The food traceability system can also provide detailed information on food production, processing, transfer, and distribution, such as the birthplace of animals, feeding, medication, date of sale, slaughtering information, and other supply chain-related information. For other food system players, traceability is part of an overall cost-effective quality management system that can also assist in continuous improvement and minimization of the impact of safety hazards, by rapidly determining and isolating its sources. Furthermore, it facilitates prompt and efficient recall of products.

Traceability is a mandatory requirement for the agri-food sector in many countries (Gandino et al. 2009; Nambiar 2010). In the European Commission Regulation No 178/2002, food traceability is a detailed procedure. Food sector business should allow the precise identification of the origin of each food product through all the production and distribution stages. Moreover, various institutions and governments monitor multiple parts of the process or enforce industrywide standards concerning food quality control. For example, the ISO 9000 standard includes determining the scope of identification of product origin and later the selection of links in the supply chain while standards and codes help achieve progress.

Regarding the traceability issue, it is worth underlining the trend of shortening the food supply chains. This distance should also include the distance between the areas of production 
M. Klimczuk-Kochańska, A. Klimczuk, Trust in Food, [in:] P.B. Thompson, D.M. Kaplan (eds.), Encyclopedia of Food and Agricultural Ethics, Second Edition, Springer, Dordrecht 2019, pp. 23802386, https://doi.org/10.1007/978-94-007-6167-4_630-1.

of other elements used in agriculture (e.g., fodder or pesticides of conventional output). As food chains have become longer and are based in multiple territories, producers and consumers are less likely to meet, which means that trust in food is less based on interpersonal relationships. This issue is related to the importance to social closeness, which assumes that economic interactions are immersed in social relations. They allow the use of coordination mechanisms and information flow resulting from social embeddedness (Uzzi 1997). Short supply chains can eliminate some of the traceability issues found in longer chains.

\section{Brand and Label Information}

Labeling gives the ability for consumers to judge the trustworthiness of the food system actors. The qualities of the certified products are detailed on the product label or through other information, such as brochures and the Internet. These labels may inform consumers about the ethical aspects of the production process just as much as the nutritional and energy value of the product. In a time when increasingly responsibility for food choices is placed on the consumer, food labels constitute a source of information the consumer can use to gauge the relative risk and trustworthiness of the food item. There is the significant importance of a visible authoritative presence in the food system to strengthen trust and provide reassurance to consumers.

Food labels are informative, particularly about a new product, or if the consumer has never tried it before; has food allergies or intolerances in the family; and to help choose food-related to some illness and diet, for example, type II diabetes, high cholesterol, heart conditions. Labels also provide freshness information about the use-by or best-before date; they help to identify product variants (e.g., flavors of yogurts, variety of orange juice - smooth or with bits); identify the country of origin (e.g., for traceability or fair trade); determine instructions for use; and determine if the product is organic, free-range, vegetarians, or vegans, as well as suitable for religious practitioners (for example, Kosher or Halal).

The labels on the packaging of products may also indicate whether the product has been covered by a certification system. Many food certification schemes are initiated by nongovernmental organizations (run by, e.g., environmentalists, animal rights activists, social activists, or traditionalists) that oppose the current construction of the global food system and are working to create an alternative system that is, for example, environmentally sustainable and socially just. These actors use food labels to channel individual consumer choices for collective action by particular political agendas. Thus, it can be argued that food labels foster 
M. Klimczuk-Kochańska, A. Klimczuk, Trust in Food, [in:] P.B. Thompson, D.M. Kaplan (eds.), Encyclopedia of Food and Agricultural Ethics, Second Edition, Springer, Dordrecht 2019, pp. 2380 2386, https://doi.org/10.1007/978-94-007-6167-4_630-1.

trust in food by promoting certain community-based norms and values in food production.

Unfortunately, the market is full of illegally labeled foods touting disease prevention or making claims such as "low fat" while having a high sodium content. "Gluten-free" applications are ubiquitous, without the backing of third-party certification such as some gluten-free certification program. Food originating from countries with a weak food safety record or questionable practices is a growing concern among consumers. For example, decreasing the package contents may be related to maintaining an illusion of the original size of the product. Moreover, many consumers, while judging the safety and quality of processed food products, use the brand as a reference to define trust in safety and quality.

\section{Conclusion}

Trust is related to voluntarily accepted duty and the risk of consumption of food. The majority of consumers, however, rely on expert systems, regulators, and the food industry to provide them with information and to minimize the impacts of risky food consumption. Thus, aspects of communication behavior, especially accuracy, adequacy, and credibility of information exchanged between the food system entities, are crucial to the development of trust in food. It helps to avoid potential losses of trust. Companies increasingly cooperate with competitors in the same industry to set standard values, spread risks, and shape opinions. Activities are driven by concerns about food safety help to establish even voluntary standards with an extensive list of competing norms, which progressively included a broader set of environmental and social concerns. Also, levels of consumer trust in food are influenced by the accuracy and degree or amount of open, honest, and transparent information exchange that takes place in those relationships.

\section{References}

Bauer, R. A. (1967). Consumer behavior as risk taking. In D. F. Cox (Ed.), Risk taking and information handling in consumer behavior (pp. 23-33). Boston: Division of Research Graduate School of Business Administration Harvard University.

Bildtgard, T. (2008). Trust in food in modern and late-modern societies. Information (International Social Science Council), 47(1), 99-128.

Gandino, F., Montrucchio, B., Rebaudengo, M., \& Sanchez, E. R. (2009). On Improving Automation by Integrating RFID in the Traceability Management of the Agri-Food 
M. Klimczuk-Kochańska, A. Klimczuk, Trust in Food, [in:] P.B. Thompson, D.M. Kaplan (eds.), Encyclopedia of Food and Agricultural Ethics, Second Edition, Springer, Dordrecht 2019, pp. 23802386, https://doi.org/10.1007/978-94-007-6167-4_630-1.

Sector. IEEE Transactions on Industrial Electronics, 56(7), 2357-2365.

Giddens, A. (1990). The consequences of modernity. Cambridge: Polity Press.

Grunert, K. G. (2002). Current issues in the understanding of consumer food choice. Trends in Food Science \& Technology, 13(8), 275-285.

Kjærnes, U., \& Dulsrud, A. (1998) Consumption and mechanisms of trust: Presented at the ESA subgroup ‘The Sociology of Consumption', University of Milan, 16-17 Sept 1998 Nambiar, A. N. (2010). Traceability in agri-food sector using RFID. 2010 International Symposium on Information Technology. Vol. 2. Kuala Lumpur: IEEE.

Poortinga, W., \& Pidgeon, N. F. (2003). Exploring the dimensionality of trust in risk regulation. Risk Analysis, 23(5), 961-972.

Shapiro, S. P. (1987). The social control of impersonal trust. American Journal of Sociology, 93(3), 623-658.

Siegrist, M., Earle, T. C., \& Gutscher, H. (2003). Test of a trust and confidence model in the applied context of electromagnetic field (EMF) risks. Risk Analysis, 23(4), 705-716.

Sztompka, P. (1999). Trust: A sociological theory. Cambridge: Cambridge University Press.

Uzzi, B. (1997). Social structure and competition in interfirm networks: The paradox of embeddedness. Administrative Science Quarterly, 42(1), 35-67. 